\title{
Hepatocyte growth factor is a predominant chemoattractant for gingival epithelial cells produced by radicular cyst-derived fibroblast-like cells
}

\author{
Mitsuhiro Ohshima, Takehisa Nishiyama, Yoshitaka Yamazaki, \\ Ryoji Yokosuka, Masao Maeno and Kichibee Otsuka \\ Department of Biochemistry, Nihon University School of Dentistry, Tokyo 101-8310
}

(Received 10 March and accepted 5 June 2000)

\begin{abstract}
To clarify whether fibroblasts could be involved in the pathogenesis of periodontal pocket formation, the chemotactic activity of radicular cystderived fibroblast-like cell (RCF)-conditioned medium (RCF-CM) for gingival epithelial cells was examined using a modified Boyden chamber assay. RCF-CM possessed significant chemotactic activity, which was decreased markedly by treatment with anti-human hepatocyte growth factor (HGF) antibody. Furthermore, the chemotactic activity of RCF-CM was well correlated with HGF content. These results show that the RCF secrete an HGF-like factor, and suggest that such a factor derived from periodontal fibroblasts might play a role in epithelial apical migration in periodontitis. (J. Oral Sci. 42, 101-106, 2000)
\end{abstract}

Key words: radicular cyst-derived fibroblast-like cell; chemotactic activity; gingival epithelial cell; hepatocyte growth factor.

\section{Introduction}

The loss of connective tissue attachment followed by epithelial down-growth is the most complicated problem in periodontitis. According to a histological view of pocket formation, Aisenberg and Aisenberg (1) hypothesised that epithelial pegs migrate in an apical direction and extend between the periodontal ligament fiber bundles before the

Correspondence to Dr. Mitsuhiro Ohshima, Department of Biochemistry, Nihon University School of Dentistry, 1-8-13, Kanda-Surugadai, Chiyoda-ku, Tokyo 101-8310, Japan fibers become detached from the cementum. For the development of epithelial down-growth, collagen fibers between root cementum and alveolar bone have to be broken down, so that epithelial tissues invade the space occupied by connective tissue.

Although the epithelial cell itself may secrete some matrix-degrading enzymes such as collagenase $(2,3)$, as we have reported previously, epithelial cells also secrete a substance that stimulates collagenase production by surrounding fibroblasts, suggesting that this co-relationship may cause periodontal disease $(4,5)$.

From another viewpoint, as several cytokines have been reported to act as chemoattractants for migrating epithelial cells (6-13), it is possible that epithelial down-growth could be induced by some factor secreted from surrounding fibroblasts. A fibroblast-derived chemotactic factor for epithelial cells in the oral region, however, has scarcely been tested. Therefore, in this preliminary study, we examined whether radicular cyst-derived fibroblast-like cells secrete some chemoattractant, such as hepatocyte growth factor, for a gingival epithelial cell line, Ca9-22.

\section{Materials and Methods}

Gingival epithelial cells

A well-characterized gingival epithelial cell line (14-17), Ca9-22 (JCRB 0625), provided by the Health Science Research Resources Bank (Osaka), was used in this study. The cells were cultured in Dulbecco's modified Eagle medium (DMEM, Iwaki) supplemented with $10 \%$ fetal bovine serum (FBS, Biowhittaker) and antibiotics (50 $\mathrm{U} / \mathrm{ml}$ penicillin, $50 \mu \mathrm{g} / \mathrm{ml}$ streptomycin, Sigma) at $37^{\circ} \mathrm{C}$ in a humidified atmosphere with $5 \% \mathrm{CO}_{2} / 95 \%$ air. The 
cells were passaged using $0.5 \%$ trypsin $/ 5.3 \mathrm{mM}$ EDTA solution (Gibco), and used as gingival epithelial cells in this study.

\section{Culture of radicular cyst-derived fibroblast-like cells (RCF)}

Connective tissues from 5 surgically removed radicular cyst walls were rinsed and dissected. All the patients gave informed consent before providing the samples. The fragments were placed on the bottom of 6-well plates (Iwaki) and covered with coverslips; each cyst tissue was separately treated. The tissue fragments were incubated for 2 weeks under the same conditions as described above. The cells derived from the explants were collected, and subcultured up to the fifth passage.

\section{Sample preparation for chemotaxis assay}

Confluent RCF cultures from 5 individual cysts were incubated in fresh DMEM supplemented with $10 \%$ FBS for a further $48 \mathrm{~h}$ under the same conditions, and the medium was separately harvested as RCF-conditioned medium (RCF-CM) to use for the epithelial cell chemotaxis assay.

Several cytokines having chemotactic activity for epithelial cells (6-13) were also used in this study; 10 $\mathrm{ng} / \mathrm{ml}$ each sample of cytokine-containing fresh DMEM supplemented with $10 \%$ FBS was used for testing epithelial cell chemotaxis. The cytokines used were as follows: recombinant human transforming growth factor- $\alpha$ (6) (TGF- $\alpha$, Gibco), recombinant human epidermal growth factor (6) (EGF, Gibco), recombinant human keratinocyte growth factor $(11,13)$ (KGF, Strathmann Biotech), recombinant human hepatocyte growth factor (13) (HGF, R\&D) and recombinant human interleukin-8 (10) (IL-8, $R \& D)$.

\section{Epithelial cell chemotaxis assay}

The chemotactic activity of each sample of RCF-CM was determined by modified Boyden chamber assay $(10,18)$ without matrix coating on the filter. Five hundred microliters of RCF-CM or cytokine-containing fresh medium was put into the lower chamber of a 24-well plate (Sumitomo Bakelite), and then the chemotaxis (upper) chamber, which had an $8-\mu \mathrm{m}$ pore filter (Chemotaxicell, Kurabo), was placed to allow application of $250 \mu 1$ of the epithelial cell suspension $\left(4 \times 10^{5}\right.$ cells $\left./ \mathrm{ml}\right)$. The epithelial cells were allowed to migrate for $40 \mathrm{~h}$ in the same atmosphere as described above. After the incubation, the upper chambers and media were discarded, and the cells that had migrated and attached to the bottom of the well were stained with crystal violet solution $[2 \%(\mathrm{w} / \mathrm{v})$ crystal violet, $0.04 \%$ (w/v) ammonium oxalate, $20 \%(\mathrm{v} / \mathrm{v})$ methanol] and counted under an inverted microscope. Four assays per specimen were performed, and chemotactic activity was calculated as means and standard deviations.

\section{Effect of anti-hHGF neutralizing antibody}

A sample of RCF-CM (case 1) was treated with 10 $\mu \mathrm{g} / \mathrm{ml}$ goat anti-human HGF neutralizing antibody (R\&D) or normal goat $\operatorname{IgG}(\mathrm{R} \& \mathrm{D})$ for $10 \mathrm{~min}$ at room temperature. The chemotactic activity of the antibody-treated RCF$\mathrm{CM}$ was determined as described above.

\section{Correlation between the HGF content and chemotactic activity}

In another experiment, the HGF content of the RCF-CM was determined with a commercially available ELISA kit (R\&D). Simultaneously, the chemotactic activities of RCF-CM for epithelial cells were determined, as described above. Correlation between chemotactic activity (mean of the four assays) and the HGF quantity (mean of the duplicate assays) was calculated using Pearson's correlation coefficient.

\section{Culture of RCF}

\section{Results}

A photomicrograph of the primary culture of fibroblastlike cells derived from the connective tissue of the radicular cyst wall is shown in Fig. 1. These cells were spindleshaped, with a so-called fibroblast-like appearance. In this study, these cells were used as RCF.

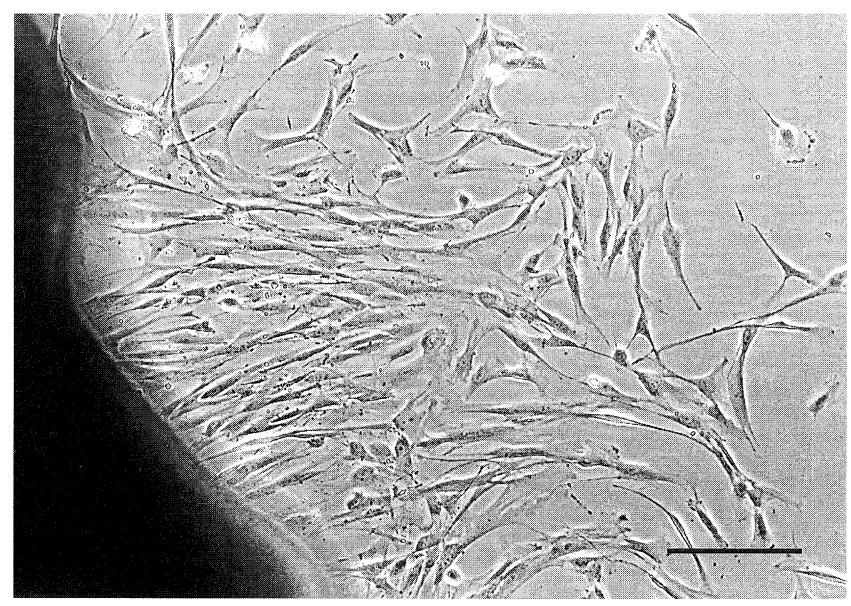

Fig. 1 Phase-contrast photomicrograph of primary culture of radicular cyst wall connective tissue-derived fibroblastlike cells. The bar represents $200 \mu \mathrm{m}$. 


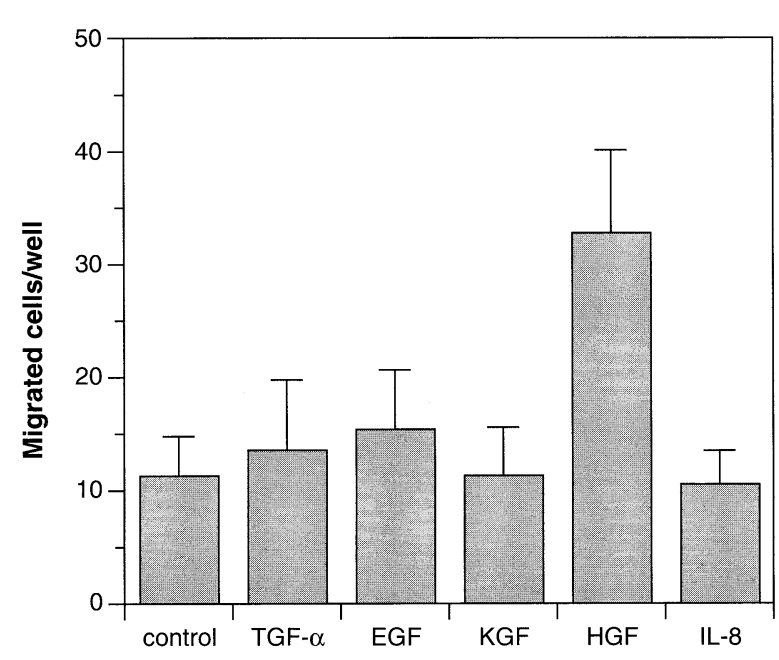

Fig. 2 Effects of cytokines on gingival epithelial cell chemotaxis. Ten $\mathrm{ng} / \mathrm{ml}$ of each cytokine-containing fresh DMEM sample supplemented with 10\% FBS was placed into the lower compartment of the chemotaxis chamber. After the cells were allowed to migrate for $40 \mathrm{~h}$, the cells attached to the bottom of the well were stained with crystal violet and counted. The results are means and standard deviations (SD) from four determinations.

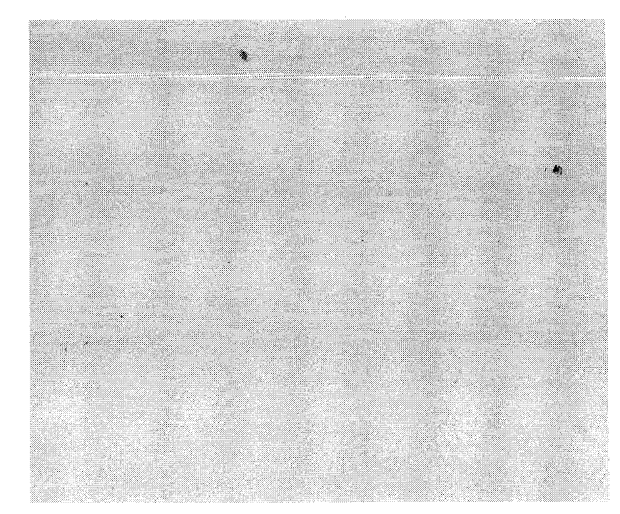

(a)

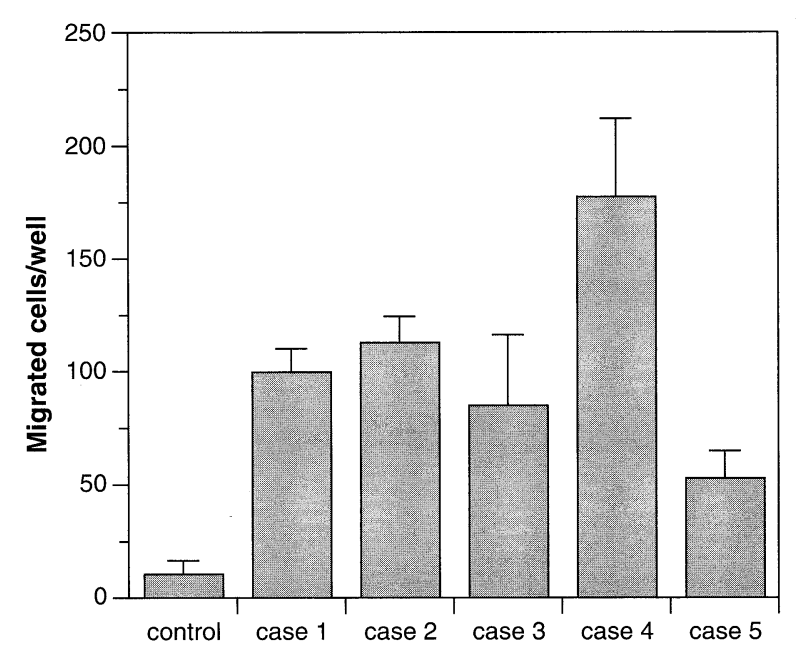

Fig. 3 Chemotactic activity of radicular cyst-derived fibroblast-like cell-conditioned medium (RCF-CM) for gingival epithelial cells. RCF-CM from 5 specimens was placed into the lower compartment of the chemotaxis chamber. After the epithelial cells were allowed to migrate for $40 \mathrm{~h}$, the cells attached to the bottom of the well were stained and counted. The results are means and SD from four determinations.

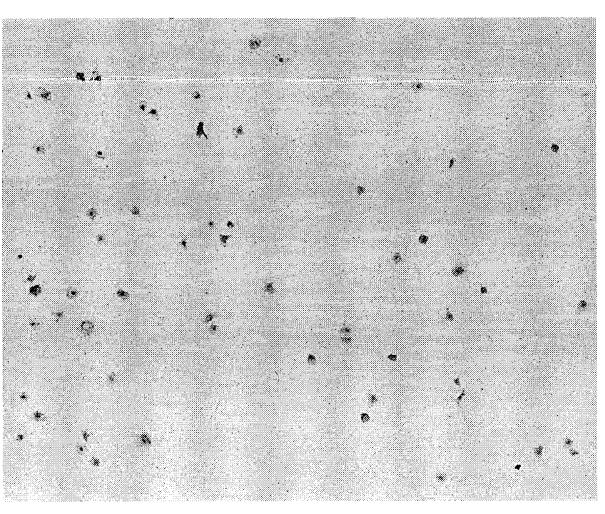

(b)

Fig. 4 Photomicrographs of migrated gingival epithelial cells. Fresh DMEM supplemented with $10 \%$ FBS (a) or RCF-CM (b) was placed into the lower compartment of the chemotaxis chamber. After the chemotaxis assays were performed, the cells attached to the bottom of the well were stained and photographed under an inverted microscope. Original magnification $\times 40$.

\section{Effects of cytokines on epithelial cell chemotaxis}

Among the cytokines used, only HGF had chemotactic activity (approximately threefold the activity of the control) for gingival epithelial cells (Fig. 2).

\section{Chemotactic activity of RCF-CM}

The chemotactic activity for gingival epithelial cells was induced by RCF-CM from 5 specimens (Fig. 3). The chemotactic activity of each specimen of RCF-CM varied, and the activity was about 5- to 20-fold that of the control.

Photomicrographs of migrated and attached cells on the bottom of the well are shown in Fig. 4. Numerous cells were attached to the bottom of the well in a test sample (b) compared with the control (a). 


\section{Effect of anti-hHGF antibody treatment}

RCF-CM treated with anti-hHGF antibody show significant decrease in chemotactic activity for epithelial cells (case 1, Fig. 5). The activity decreased to approximately a quarter of the activity of RCF-CM without antibody treatment. Similar results were obtained for the other four RCF-CM (cases 2-5, data not shown).

\section{Correlation between the chemotactic activity and HGF content}

Correlation between the chemotactic activity of $5 \mathrm{RCF}-$ CM samples and HGF content is shown in Fig. 6. The chemotactic activity was well correlated to HGF content (correlation coefficient, $r=0.983$ ).

\section{Discussion}

HGF acts as a mitogen, motogen, morphogen, and antiapoptotic factor for various kinds of epithelial cells (1921 ), and also acts as a scatter factor (SF). It is a protein secreted by fibroblasts and promotes motility and matrix invasion of epithelial cells (9). For medical use, HGF is expected to treat disorders such as hepatitis owing to its regenerative action; however, it activates some types of tumor cell invasion and metastasis with its characteristics as an SF (21). For the above reasons, we assume that epithelial down-growth following the loss of connective

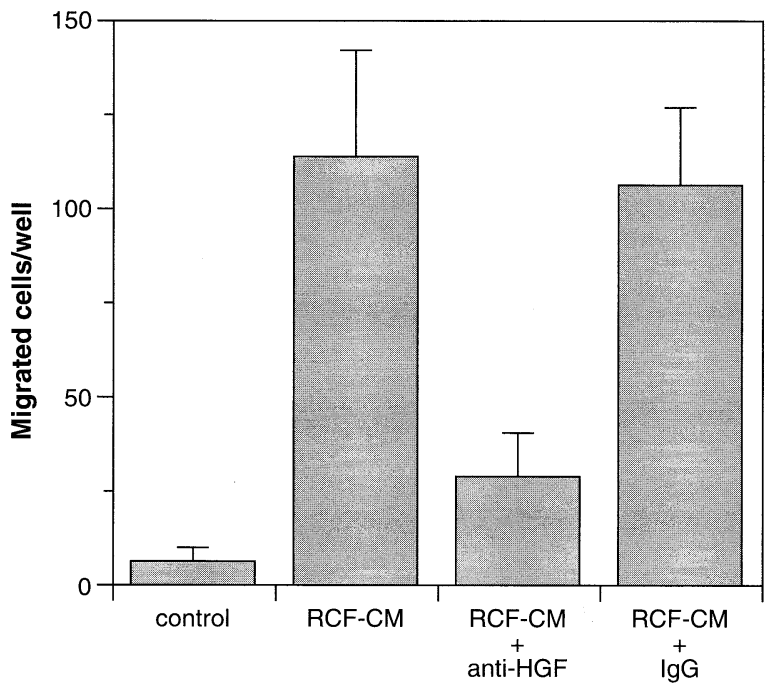

Fig. 5 Effect of anti-human HGF neutralizing antibody. A sample of RCF-CM was treated with $10 \mu \mathrm{g} / \mathrm{ml}$ of antihuman HGF neutralizing antibody or normal goat IgG for $10 \mathrm{~min}$ at room temperature. Then, gingival epithelial cell chemotaxis assays were performed as described in Fig. 3. tissue attachment could be induced by HGF/SF or by an HGF-like factor. Our preliminary but obvious results clearly demonstrate that RCF secrete some chemotactic factor for gingival epithelial cells. Furthermore, the chemotactic activity of RCF-CM was significantly decreased by the treatment with anti-hHGF neutralizing antibody, suggesting that the major chemotactic factor existing in RCF-CM is HGF itself or a closely related factor. Neaud et al. (18) reported a similar observation, that chemotactic (invasive) activity for hepatocellular carcinoma cells by a myofibroblast-derived factor was completely blocked by anti-hHGF antibody. However, the chemotactic activity of RCF-CM was not completely inhibited by antihHGF treatment in this study, indicating that RCF-CM contains some other chemoattractants.

HGF expression in periodontal stromal cells has been little reported $(22,23)$. Sugiyama et al. $(23)$ reported that lipoteichoic acid and interleukin-1 synergistically stimulate HGF production by gingival fibroblasts in culture. They also demonstrated that recombinant hHGF stimulates DNA synthesis by epithelial cells, but they did not test HGF action as a chemoattractant. Further investigation is needed to clarify which factor, such as HGF/SF, is actually involved in the apical migration of epithelial cells in periodontitis. Now we are investigating whether gingival or periodontal ligament fibroblasts secrete some chemoattractant for gingival epithelial cells.

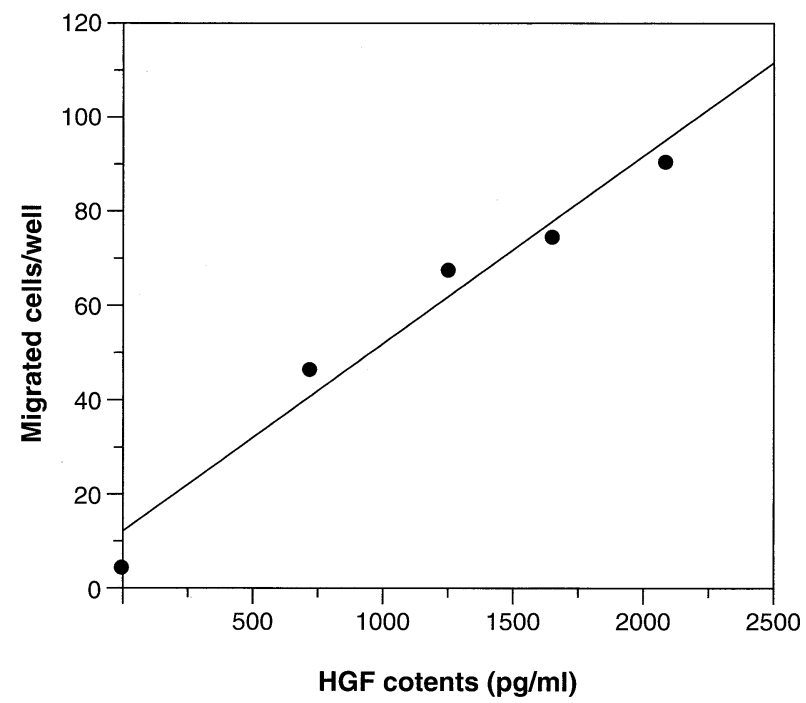

Fig. 6 Correlation between the HGF content and chemotactic activity. Correlation between the HGF content in RCFCM was measured by ELISA and its chemotactic activity was calculated. They were well-correlated (correlation coefficient, $\mathrm{r}=0.983$ ). 
We used connective tissue-derived fibroblast-like cells from radicular cyst walls as a source of fibroblastconditioned media. One of the reasons arose from an observation reported by Gao et al. (24). Their study revealed that stromal cells expressing keratinocyte growth factor (KGF) exist just beneath the proliferating antral lining of epithelial cells of apical lesions. As KGF is a stromaderived, potent mitogen for epithelial cells $(11,13,25)$, we assumed that KGF-expressing cells simultaneously express HGF, as reported by Li and Tseng (26).

Receptors for HGF (c-Met protein) mRNA are coded as $c$-met $(9,20,21)$. We have shown by reverse transcriptase polymerase chain reaction that not only the gingival epithelial cell line (Ca9-22), but also the radicular cyst lining epithelium, express mRNA for $c$-met (submitted). The epithelial lining of a radicular cyst is thought to originate from the epithelial cell rests of Malassez (27), and these cells are likely to respond some kinds of growth factors (28-30). Spouge (31-33) has suggested repeatedly that there is a relationship between the epithelial cell rests of Malassez and chronic marginal periodontitis. If the epithelial cell rests of Malassez express c-met, and respond to HGF/SF produced by periodontal stromal fibroblasts, it would not be surprising if they facilitate apical migration of the junctional epithelium during the pathogenesis of periodontal pocket formation.

\section{Acknowledgments}

This study was supported in part by a Grant-in-Aid for Scientific Research (A-1, \#10307054) from the Ministry of Education, Science, Sports and Culture of Japan.

\section{References}

1. Aisenberg, M.S. and Aisenberg, A.D. (1948) A new concept of pocket formation. Oral Surg. Oral Med. Oral Pathol. 1, 1047-1055

2. Limeback, H. and Brunette, D. M. (1981) Latent collagenase is produced in vitro by epithelial cells derived from the cell rests of Malassez. J. Dent. Res. 60 (Special Issue), 345

3. Salonen, J., Uitto, V-J., Pan, Y-M. and Oda, D. (1991) Proliferating oral epithelial cells in culture are capable of both extracellular and intracellular degradation of interstitial collagen. Matrix 11, 4355

4. Ohshima, M., Taguchi, M., Ogoshi, T., Fujikawa, K., Ito, K. and Otsuka, K. (1995) Stimulation of human periodontal ligament fibroblast collagenase production by a gingival epithelial cell-derived factor. J. Periodontal Res. 30, 220-228
5. Ohshima, M., Ogoshi, T., Ogawa, H., Muto, A., Suzuki, K. and Otsuka, K. (1997) Effect of dental cyst epithelium-conditioned medium on collagenase production by periodontal ligament fibroblasts. J. Nihon Univ. Sch. Dent. 39, 31-33

6. Barrandon, Y. and Green, H. (1987) Cell migration is essential for sustained growth of keratinocyte colonies: the roles of transforming growth factor$\alpha$ and epidermal growth factor. Cell 50, 1131-1137

7. Stoker, M., Gherardi, E., Perryman, M. and Gray, J. (1987) Scatter factor is a fibroblast-derived modulator of epithelial cell mobility. Nature 327, 239-242

8. Nakamura, T., Nishizawa, T., Hagiya, M., Seki, T., Shimonishi, M., Sugimura, A., Tashiro, K. and Shimizu, S. (1989) Molecular cloning and expression of human hepatocyte growth factor. Nature 342 , $440-443$

9. Naldini, L., Weidner, K.M., Vigna, E., Gaudino, G., Bardelli, A., Ponzetto, C., Narsimhan, R.P., Hartmann, G., Zarnegar, R., Michalopoulos, G.K., Birchmeier, W. and Comoglio, P.M. (1991) Scatter factor and hepatocyte growth factor are indistinguishable ligands for the MET receptor. EMBO J. 10, 2867-2878

10. Michel, G., Kémeny, L., Peter, R.U., Beetz, A., Ried, C., Arenberger, P. and Ruzicka, T. (1992) Interleukin-8 receptor-mediated chemotaxis of normal human epidermal cells. FEBS Lett. 305, 241-243

11. Tsuboi, R., Sato, C., Kurita, Y., Ron, D., Rubin, J.S. and Ogawa, H. (1993) Keratinocyte growth factor (FGF-7) stimulates migration and plasminogen activator activity of normal human keratinocytes. J. Invest. Dermatol. 101, 49-53

12. Gyulai, R., Hunyadi, J., Kenderessy-Szabo, A., Kemeny, L. and Dobozy, A. (1994) Chemotaxis of freshly separated and cultured human keratinocytes. Clin. Exp. Dermatol. 19, 309-311

13. Sato, C., Tsuboi, R., Shi, C-M., Rubin, J.S. and Ogawa, H. (1995) Comparative study of hepatocyte growth factor/scatter factor and keratinocyte growth factor effects on human keratinocytes. J. Invest. Dermatol. 104, 958-963

14. Gamou, S. and Shimizu, N. (1987) Change in metabolic turnover is an alternate mechanism increasing cell surface epidermal growth factor receptor levels in tumor cells. J. Biol. Chem. 262, 6708-6713

15. Hirai, M., Gamou, S., Minoshima, S. and Shimizu, 
N. (1988) Two independent mechanisms for escaping epidermal growth factor-mediated growth inhibition in epidermal growth factor receptor-hyperproducing human tumor cells. J. Cell Biol. 107, 791-799

16. Hirai, M. and Shimizu, N. (1990) Purification of two distinct proteins of approximate $\mathrm{Mr} 80000$ from human epithelial cells and identification as proper substrates for protein kinase C. Biochem. J. 270, 583589

17. Matsumoto, K., Matsumoto, K., Nakamura, T. and Kramer, R.H. (1994) Hepatocyte growth factor/ scatter factor induces tryrosine phosphorylation of focal adhesion kinase $\left(\mathrm{p} 125^{\mathrm{FAK}}\right)$ and promotes migration and invasion by oral squamous cell carcinoma cells. J. Biol. Chem. 269, 31807-31813

18. Neaud, V., Faouzi, S., Guirouilh, J., Le Bail, B., Balabaud, C., Bioulac- Sage, P. and Rosenbaum, J. (1997) Human hepatic myofibroblast increase invasiveness of hepatocellular carcinoma cells: evidence for a role of hepatocyte growth factor. Hepatology 26, 1458-1466

19. Montesano, R, Matsumoto, K., Nakamura, T. and. Orci,L. (1991) Identification of a fibroblast-derived epithelial morphogen as hepatocyte growth factor. Cell 67, 901-908

20. Derman, M., Cunha, M.J., Barros, E.J.G., Nigam, S.K. and Cantley, L.G. (1995) HGF-mediated chemotaxis and tubulogenesis require activation of the phosphatidylinositol 3-kinase. Am. J. Physiol. 268, F1211-F1217

21. Matsumoto, K. and Nakamura, T. (1997) Hepatocyte growth factor (HGF) as a tissue organizer for organogenesis and regeneration. Biochem. Biophys. Res. Commun. 239, 639-644

22. Tamura, M., Arakaki, N., Tsubouchi, H., Takada, H. and Daikuhara, Y. (1993) Enhancement of human hepatocyte growth factor production by interleukin$1 \alpha$ and $-1 \beta$ and tumor necrosis factor- $\alpha$ by fibroblasts in culture. J. Biol. Chem. 268, 8140-8145

23. Sugiyama, A., Arakaki, R., Ohnishi, T., Arakaki, N., Daikuhara, Y and Takada, H. (1996) Lipoteichoic acid and interleukin 1 stimulate synergistically production of hepatocyte growth factor (scatter factor) in human gingival fibroblast in culture. Infect. Immun. 64, 1426-1431

24. Gao, Z., Flaitz, C.M. and Mackenzie, I.C. (1996) Expression of keratinocyte growth factor in periapical lesions. J. Dent. Res. 75, 1658-1663

25. Finch, P.W., Rubin, J.S., Miki, T., Ron, D. and Aaronson, S.A. (1989) Human KGF is FGF-related with properties of a paracrine effector of epithelial cell growth. Science 245, 752-755

26. Li, D-Q. and Tseng, S.C.G. (1997) Differential regulation of keratinocyte growth factor and hepatocyte growth factor/scatter factor by different cytokines in human corneal and limbal fibroblasts. J. Cell. Physiol. 172, 361-372

27. Ten Cate, A.R. (1972) The epithelial cell rests of Malassez and the genesis of the dental cyst. Oral Surg. Oral Med. Oral Pathol. 34, 956-964

28. Grupe, H.E.Jr., Ten Cate, A.R. and Zander, H.A. (1967) A histochemical and radiobiological study of in vitro and in vivo human epithelial cell rest proliferation. Arch. Oral Biol. 12, 1321-1329

29. Johansen, J.R. (1970) Incorporation of tritiated thymidine by the epithelial rests of Malassez after attempted extraction of rat molars. Acta Odontol. Scand. 28, 463-470

30. Thesleff, I. (1987) Epithelial cell rests of Malassez bind epidermal growth factor intensely. J. Periodontal Res. 22, 419-421

31. Spouge, J.D. (1980) A new look at the rests of Malassez. A review of their embryological origin, anatomy, and possible role in periodontal health and disease. J. Periodontol. 51, 437-444

32. Spouge, J.D. (1984) The rests of Malassez and chronic marginal periodontitis. J. Clin. Periodontol. $11,340-347$

33. Spouge, J.D. (1986) A study of epithelial odontogenic residues in the pig. J. Periodontol. 57, $164-171$ 